GEOUSP - Espaço e Tempo, São Paulo, № 20, pp. 213 - 234, 2006

\title{
TESES DE DOUTORADO E DISSERTAÇÕES DE MESTRADO DEFENDIDAS
}

\author{
(Maio de 2006 a Outubro de 2006)
}

\section{Teses de Doutorado}

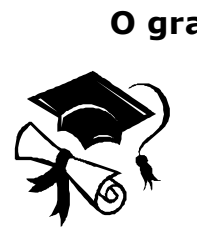

O grande cerrado do Brasil central: geopolítica e economia

Bernardo Palhares Campolina Diniz

Orientador: Prof. Dr. Wanderley Messias da Costa

O objetivo desta tese é analisar o processo de ocupação do Grande Cerrado do Brasil Central no que diz respeito à economia e à geopolítica. Avaliamse alguns aspectos físico-naturais fundamentais para a interpretação deste processo, procurando mostrar a diversidade do Cerrado brasileiro e as implicações desta diversidade sobre a agricultura, especialmente a aptidão agrícola. Discorre-se sobre aspectos da história da ocupação da região Central do Brasil, procurando chamar a atenção para os pontos históricos que marcaram a formação territorial regional. Resgata-se a influência da geopolítica e traça-se um paralelo entre as diversas políticas públicas e as suas implicações sobre o território. Discute-se a construção de Brasília, resgatando os seus antecedentes históricos e o que sua construção representou para o crescimento da região. Analisam-se alguns dos determinantes da ocupação recente do Cerrado brasileiro - dos anos 1960 até os dias atuais. Para isso, resgata-se o processo de modernização da agricultura brasileira e os principais instrumentos de política utilizados para que a agricultura brasileira entrasse em uma nova fase, dentre os quais a criação do Sistema Nacional de Crédito Rural (SNCR) e os programas de incentivo à incorporação produtiva do Cerrado, como o Polocentro e o Prodecer, além daqueles voltados para a abertura de estradas e a colonização pública e privada. Traça-se um panorama da estrutura produtiva da região, a partir de 1975, com destaque para os principais produtos agropecuários (arroz, feijão, soja, milho, algodão e boi) e a agroindústria, buscando identificar as áreas para onde se dirigiu a produção. Resgata-se o mapa de aptidão agrícola e é analisada a coerência entre as áreas para onde a produção se expandiu e aquelas que têm melhor aptidão agrícola. Analisa-se, ainda, o binômio soja-boi e a conformação do complexo grãos-carne em parte da região. Busca-se caracterizar a agroindústria com ênfase na indústria frigorífica, na indústria processadora de soja e no setor sucroalcooleiro. Em seguida, analisa-se o crescimento populacional e a constituição da malha urbana da região. Discute-se a importância da cidade no processo de desenvolvimento regional e apontam-se os principais trabalhos sobre o tema desenvolvidos no Brasil. Procura-se mostrar que o crescimento da região foi muito diferenciado interregionalmente, o que deu origem a uma malha urbana diferenciada segundo sua função. Mostrase ainda que o crescimento populacional nas últimas três décadas ocorreu ao longo dos principais eixos de transporte da região. Conclui-se que o meio natural influi sobre o processo de localização das atividades agropecuárias e suscita o debate acerca da necessidade de industrialização da região para que a mesma possa manter seu patamar de desenvolvimento e crescimento. Mostra-se que, diferentemente do que o censo comum supõe, o Cerrado é heterogêneo e seu desenvolvimento vem gerando disparidades regionais significativas - áreas muito desenvolvidas e áreas muito atrasadas-, cujo resultado pode ser verificado em alguma medida por meio da análise da rede urbana da região.

$$
\text { exes ex }
$$




\section{A exploração de pedreiras na região metropolitana de São Paulo no contexto do planejamento e gestão do território}

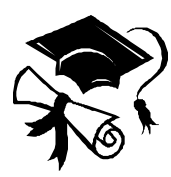

Cleide Poletto

Orientador: Profa. Dra. Ana Maria Marques Camargo Marangoni

Este trabalho apresenta uma avaliação do planejamento urbano e regional realizado na região metropolitana da Grande São Paulo, no que se refere a exploração de minerais não metálicos usados na produção de agregados para a construção, mais especificamente as pedreiras. Adota como premissa a inexistência de uma política específica para esse setor da economia, e demonstra a inter-relação entre o desenvolvimento urbano e o consumo de brita, dando destaque para a necessidade de harmonizar o desenvolvimento social e econômico com a preservação ambiental. Constata a crescente demanda por rochas britadas e identifica os impactos ambientais advindos desse tipo de exploração mineral. Avalia os principais

\section{eses eses}

Condições para a constituição de um patrimônio ambiental urbano : proposta de focos qualitativos no centro de São Paulo

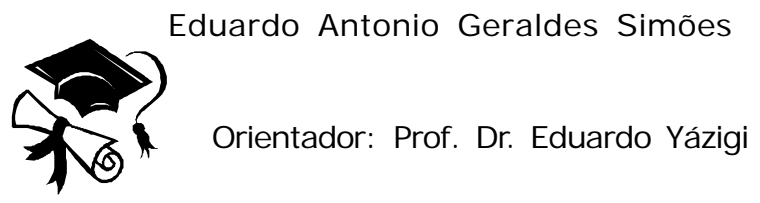

O presente trabalho pretende contribuir com o aprofundamento da discussão em torno das dinâmicas espaciais urbanas materializadas nas permanências e transformações na paisagem urbana. A partir de tais dinâmicas se constituem os patrimônios históricos e culturais como proposta institucional para a consolidação e a permanência de determinados valores e identidades significativas. aspectos legais envolvidos na regulamentação dessa atividade extrativa, enfatizando as normas relativas à mineração e ao meio ambiente. Com relação à região da Grande São Paulo, identifica as origens da sua institucionalização e a implantação do planejamento regional integrado, bem como avalia os estudos e projetos realizados pela EMPLASA, principalmente durante a década de 1980, para organizar aquele setor da economia. Os estudos realizados constataram ser a experiência, na região metropolitana paulista, pioneira na tentativa de organização do setor da mineração em nível regional; confirmaram a premissa de que o Estado não dispõe de política para organizar esse setor, embora já tenha produzido uma quantidade significativa de dados e informações que hoje se encontram dispersos e carentes de atualização. Nos aspectos legais identificou superposição e conflitos de atribuições que, somados à imprecisão de conceitos, acabam por dificultar o atendimento aos objetivos pretendidos. Conclui observando que a experiência acumulada e documentada nos próprios órgãos do Estado pode fornecer os elementos básicos para a elaboração de uma política para esse setor da indústria extrativa, com resultados social e economicamente desejáveis.

O objetivo geral é fornecer subsídios para compreensão de tais dinâmicas a partir da dimensão cultural da cidade, tomando o Centro de São Paulo como objeto. O objetivo específico é identificar e compreender as condições em que se constituem os significados do patrimônio ambiental urbano a partir das práticas sociais. Neste sentido, proponho a noção de focos qualitativos como lugares portadores de um potencial de significação que, independentemente de incluírem elementos arrolados oficialmente como bens patrimoniais, desempenham o papel de referência, orientação e identidade espacial na perspectiva do espaço vivido e do cotidiano do habitante. Esta hipótese implica em que os focos qualitativos constituam instrumento para a formulação das condições de qualificação do espaço urbano através da compreensão dos modos pelos quais os valores propostos pelo patrimônio ambiental urbano são vivenciados e apropriados nas práticas sociais e no cotidiano. 


\section{A construção do patrimônio natural}

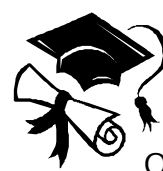

Orientador: Prof. Dr. Wagner Costa Ribeiro

Este trabalho discute o significado da proteção do patrimônio natural no processo de produção do espaço geográfico do litoral norte paulista. Parte inicialmente da apresentação da trajetória de construção do conceito de patrimônio natural e das políticas públicas para a sua proteção, em diferentes esferas (nos planos internacional, federal e regional). Procura demonstrar, de um lado, que essa proteção - que se deu via tombamento da Serra do Mar - foi instituída para fazer frente à urbanização acelerada do litoral nos anos 1980 e, de outro lado, que ela foi incorporada à produção espacial, passando a representar uma nova condição para o processo. A proteção da natureza tornou-se uma condição necessária à reprodução do papel que o litoral norte desempenha na divisão espacial do trabalho da metrópole paulista: o de zona de veraneio de determinados segmentos sociais. A proteção da natureza aparece, ao mesmo tempo, como produto do urbano e como condição para sua reprodução.
Diferenciação sócio-econômica e campesinato : o caso dos assentamentos Cristo Rei, Ubá e Rio Branco no Sudeste do Pará

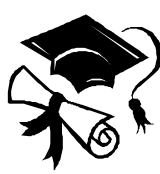

Cátia Oliveira Macedo

Orientador: Prof. Dr. Ariovaldo Umbelino de Oliveira

Esta tese é resultado de uma pesquisa desenvolvida nos assentamentos Cristo Rei (Itupiranga-Pa), Ubá (São Domingos do Araguaia-Pa) e Rio Branco (ParauapebasPa). Buscamos abordar o tema da diferenciação social do campesinato através dos estudos destes assentamentos. Tomamos como ponto de partida a reconstituição da história de luta pelo acesso a terra. Objetiva-se com isso entender como as diferentes estratégias de ocupação da terra têm influenciado formas particulares de organização destes grupos sociais. Isto implica, por sua vez, na reflexão sobre os condicionantes da forma de produção do espaço agrícola pelo camponês destas áreas e seus mecanismos de reprodução social. Verificamos que as mais variadas ações para a conquista da terra sejam elas coletivas $3 / 4$ como as ligadas aos movimentos sociais $3 / 4$ ou individuais $3 / 4$ como a abertura de posse por famílias ou pequenos grupos de posseiros na região $3 / 4$ refletem diretamente na organização interna do assentamento e sua relação com os mais variados segmentos sociais e institucionais. O trabalho então discorre acerca das diferentes formas em que a diferenciação do campesinato nesta parte da Amazônia pode ocorrer. 


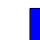

216 - GEOUSP - Espaço e Tempo, São Paulo, № 20, 2006

\section{O uso da informação geográfica na área de sáude no Brasil}

João Evangelista de Souza Lima Neto

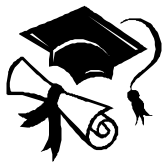

Orientador: Prof. Dra. Sonia Maria Vanzella Castellar

Ao identificarmos as dificuldades da incorporação do conhecimento geográfico nas análises do processo saúde-doença, buscamos desenvolver uma reflexão sobre a relação entre informação e conhecimento geográfico, partindo de uma discussão sobre os conceitos de informação e conhecimento, visando a definição de um conceito de informação geográfica, bem como ao seu desenvolvimento. Discutimos também o processo de organização da informação sob os referenciais da Ciência da Informação, buscando estabelecer referenciais para discutir a organização da informação geográfica, com destaque para os Sistemas de Informação Geográfica. Em seguida discutimos o desenvolvimento da relação entre geografia e saúde e o papel dos Sistemas de Informação Geográfica na área de saúde, para finalmente traçar uma caracterização do uso da informação geográfica na área de saúde no Brasil, através da análise da produção divulgada nos periódicos Cadernos de Saúde Pública e Revista de Saúde Pública, no período de 1999 a 2005. Ao final fazemos uma reflexão do papel da informação geográfica na área de saúde no Brasil, buscando discutir o papel que a organização da informação na área de Geografia pode desempenhar para uma intensificação do uso da informação geográfica na área de saúde.

$$
\text { ceseres }
$$

O turismo em espaço rural como modo de valorização do patrimônio cultural : estudo de casos na média depressão periférica paulisas: as fazendas Capoava e Ibicaba)

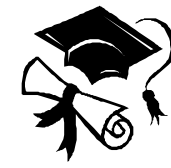

Ricardo Fernandes Faustino

Orientador: Prof. Dr. Adilson Avansi de Abreu

O presente estudo objetiva analisar o turismo em espaço rural como modo de valorização do patrimônio cultural. Após a reflexão teórica estudam-se duas fazendas que praticam o turismo em espaço rural no Estado de São Paulo. Elas representam as paisagens culturais, regionais e locais produzidas pelo homem nos séculos XVIII, XIX e XX.Por meio de questionários e trabalhos de campo, busca-se avaliar as opiniões dos turistas e dos donos dessas fazendas para se aferir o relacionamento entre o homem a paisagem e a cultura.Essas fazendas possibilitam ao turista um contato direto com a cultura e a natureza que remontam aquela época.O relacionamento humano e estas possibilidades oferecidas pelo turismo em espaço rural tornam-se fator primordial para se checar a viabilidade das propostas de enaltecer a cultura destas fazendas e suas respectivas paisagens à luz da geografia e do turismo.Embasados na teoria sistêmica, na teoria da região e no turismo, busca-se a verificação, neste estudo de casos das fazendas Capoava e Ibicaba, situadas nas regiões de ltu e Limeira,do no Estado de São Paulo. 
Unidades de vegetação e pastagens nativas do pantanal da Nhecolândia, Mato Grosso do Sul

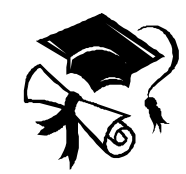

\section{Luciana Graci Rodela}

Orientador: Prof. Dr. José Pereira de Queiroz Neto

Este estudo foi realizado na Fazenda Nhumirim, propriedade da EMBRAPA Pantanal, Nhecolândia, Pantanal do Mato Grosso do Sul. Diante da necessidade do reconhecimento dos elementos do meio ambiente natural, bem como de sua dinâmica, para a busca do equilíbrio ambiental na região, esta pesquisa teve como objetivo estudar a vegetação da Nhecolândia.A Nhecolândia é uma das mais expressivas regiões criatórias de gado de corte do Brasil. As pastagens nativas correspondem a grande variedade de unidades de vegetação, de campos a cerrados. O uso espacial e temporal dessas pastagens por bovinos, sua disponibilidade, qualidade e produtividade pecuária são influenciados pelas condições ambientais, principalmente inundações e precipitações.Para conservação e utilização sustentável dos recursos naturais no Pantanal, é de grande importância mapear as principais unidades ambientais, estabelecer unidades de vegetação/pastagens para conhecer as áreas de sobrevivência de espécies de animais, visto que o Pantanal corresponde à uma coleção de ambientes de equilibrio dinâmico frágil; a planície possui declividades baixissimas que provocam um deslocamento extremamente lento das águas, a dinâmica hídrica é particular: as chuvas e os rios abastecem os lençóis freáticos causando inundações; e a alimentação do rebanho baseia-se quase que integralmente em pastagens nativas.Tendo em vista a utilização da vegetação como pastagem, houve necessidade de estudar as relações entre os tipos de vegetação, especialmente as campestres, e seus ambientes de ocorrência. Se fez necessário propor uma classificação para vegetação e mapeamento local das unidades de vegetação, relacionando-a aos ambientes de ocorrência, com vistas à extrapolação para o pantanal da Nhecolândia. A vegetação foi classificada como: Unidade Habitualmente Seca, Unidade Habitualmente Sazonal e Unidade Habitualmente Úmida, as quais apresentam diferenças quanto à preferência pelos bovinos, às características florísticas, fisionômicas e, principalmente quanto a umidade habitual do solo, em função da topografia e das precipitações pluviométricas ao longo do ano

$$
\text { exeses }
$$

\section{O lugar do turismo na ciência geográfica : contribuições teórico-metodológicas à ação educativa}

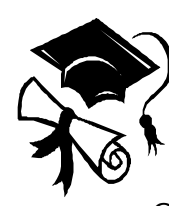

Nair Apparecida Ribeiro de Castro

Orientador: Profa. Dra. Regina Araújo de Almeida

O estudo que apresentamos traduz a busca pelo conhecimento do lugar assumido pelo turismo no contexto da ciência geográfica com o objetivo de amealhar contribuições que dêem suporte teórico-prático aos docentes envolvidos com a formação do geógrafo nos cursos de licenciatura e de bacharelado. De início, analisamos o caráter dual do turismo como prática social e atividade produtiva. Em seguida fazemos uma revisão teórica das categorias geográficas Território, Lugar e Paisagem sem perder de vista esse caráter dual na perspectiva de uma abordagem geográfica. O resultado obtido nos conduz à visão preliminar de contribuições teórico-metodológicas na área de intercessão da Geografia com o Turismo. Empreendemos, num "tour epistemológico", a busca das raízes do interesse do geógrafo por esta temática. Recuperamos a historicidade desse 

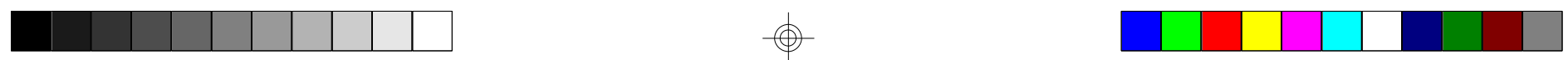

conhecimento, identificando-o com a própria evolução do pensamento geográfico. Iniciamos essa viagem de estudos no período clássico, passamos pela Geografia Moderna e daí às renovações paradigmáticas dos anos 50 e 70 do século $X X$, com as contribuições das abordagens Pragmática, Crítica, Humanista, Cultural e Socioambiental. A análise de modelos elaborados por geógrafos internacionais, inicialmente neopositivistas e, posteriormente, voltados para a abordagem sinalizadora da pluralidade paradigmática, evidencia a preocupação epistêmica com a organização do espaço turístico. Esses estudos tematizam e colocam desafios à produção desse conhecimento, cuja discussão se apresenta indispensável ao seu avanço e aprimoramento. Tomando esse construto como referência, partimos para conhecer a produção acadêmica brasileira em dissertações e teses, num universo de 162 produções, defendidas em 22 departamentos de geografia de instituições pública e privada do país. Essa pesquisa nos revela a tendência pluriparadigmática formadora, tanto da base de sustentação teórica, como da base conceitual e temática que referencia a produção brasileira na abordagem geográfica do turismo. No sentido de verticalizar nossa contribuição à formação do geógrafo, relatamos uma experiência pedagógica na disciplina "Geografia do Turismo" do Departamento de Geografia da Faculdade de Filosofia, Letras e Ciências Humanas da USP, da qual participamos no ano de 2002 e analisamos programas de ensino da disciplina Geografia do Turismo, desenvolvidos no Departamento de Geografia da Universidade Federal do Paraná Brasil, e em mais cinco países - Itália, Espanha, Costa Rica, Canadá e EUA. A avaliação de nosso experimento somada às análises curriculares que empreendemos colocam em evidência a pluralidade de focos, enfoques e bases conceituais que as abordagens geográficas do turismo ensejam. 


\section{Dissertassões de Mestrado}

\begin{abstract}
A organização e inserção da produção de pequenas unidades agrícolas nos mercados paulistanos : os agricultores do bairro rural de Santo Ângelo
\end{abstract}

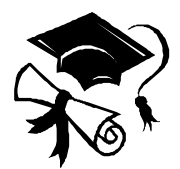

Antônio Carlos da Paz Santana

Orientador: Prof. Dra. Marta Inez Medeiros Marques

Este trabalho discute, a partir de um estudo sobre o bairro rural Santo Ângelo, localizado no município de Mogi das Cruzes (maior centro atual de hortaliças), como os agricultores organizam sua produção a partir do sistema agrícola e da inserção da produção nos mercados da cidade de São Paulo. A análise deste tema, permitiu que se compreendesse o funcionamento do sistema de abastecimento de alimentos frescos para os grandes centros urbanos; os diferentes equipamentos de comercialização e de distribuição do mercado.Partindo do pressuposto de que as pequenas unidades de produção familiar são frutos da contradição do modo de produção capitalista, chega-se à conclusão de que à subordinação aos mercados é a principal causa da ocorrência do processo de desintegração, embora os agricultores, na qualidade de posseiros, encontram na organização política a maneira de permanecerem produzindo.

\section{A evolução do poder aeroespacial brasileiro}

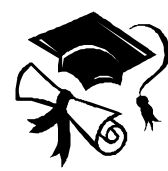

André Luiz de Almeida

Orientador: Prof. Dr. André Roberto Martin

A presente dissertação em Geografia Política tem como objetivo realizar uma análise do poder aeroespacial brasileiro do início do século XX aos dias atuais. Na primeira parte, de caráter geral, é descrita a teoria do poder aéreo, seus principais teóricos, sua aplicação nas guerras e como esse poder converteu-se em aeroespacial ao longo do século passado. Em seguida, é apresentada a constituição e evolução dos elementos que compõem o poder aeroespacial brasileiro, que são representados pela aviação civil, infra-estrutura aeroespacial, complexo científicotecnológico aeroespacial, Força Aérea Brasileira $(F A B)$, programa espacial e industrial aeroespacial. Após a descrição de cada um desses elementos, é feita uma avaliação dos aspectos estratégicos do poder aeroespacial para o Brasil do ponto vista geopolítico, científico, militar e econômico, que é complementada pelas considerações finais do autor da pesquisa.
Território e guerra fiscal : a perversidade dos incentivos territoriais

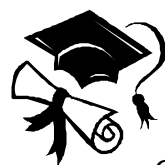

Pablo Ibañez

Orientador: Prof. Dra. Maria Adélia Aparecida de Souza
Ao longo da década de 90 algumas transformações marcaram o Brasil. Entre elas, se destacam: o ingresso do país no processo de globalização, o aumento dos fluxos internacionais de investimento, a maior descentralização político-administrativa promovida pela Constituição de 1988 e, ainda, a diminuição das políticas de desenvolvimento regional do governo federal.Nesse contexto, os 

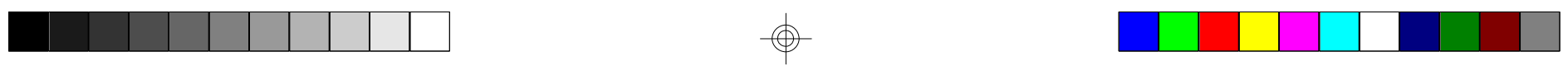

governos subnacionais intensificaram a prática de políticas individuais e competitivas para atrair investimentos, evento que foi denominado guerra fiscal.O objetivo da presente dissertação é entender o papel do território na guerra fiscal e as conseqüencias territoriais decorrentes desse evento. Para isso, analisamos a competição entre estados pela atração de investimentos do setor automotivo e o aprofundamento da guerra fiscal nos municípios.
Sabemos que a tecnoesfera revela elementos fundamentais para a análise, mas demos também a devida ênfase à psicoesfera que envolve esse evento. $E$, finalmente, tratamos dos desdobramentos da Reforma Tributária do governo Lula, que de alguma forma conduziu a novos conflitos entre estados. Mais do que uma guerra fiscal, uma visão renovada da geografia permite entendê-la como uma guerra dos lugares.

\section{exter ex}

\section{Estudo das modificações nos padrões de uso e cobertura da terra com auxílio de imagens multitemporais de sensoriamento remoto na bacia do Taiaçupeba, região metropolitana de São Paulo}

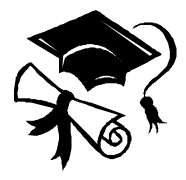

Paulo de Almeida Correia Júnior

Orientador: Prof. Dr. Mário De Biasi

A elaboração de modelos pode ser entendida como um processo de simplificação da realidade. Desta forma, foram utilizados neste trabalho dados multitemporais estatísticos e de sensoriamento remoto, para que fossem caracterizadas as mudanças nos padrões de uso e cobertura da terra na bacia do Taiaçupeba nos últimos 30 anos. Para uma melhor aferição das informações obtidas a partir de imagens de satélite e uma posterior verificação das mesmas, foi necessária a utilização de dados colhidos durante levantamentos de campo, bem como o uso de estatísticas oficiais e trabalhos científicos sobre a área de estudo, dando ao presente trabalho um papel de complementação e atualização desses últimos.

$$
\text { extes ex }
$$

\section{Negros congadeiros e a cidade : costumes e tradições nos lugares e nas redes da congada de Uberlândia-MG}

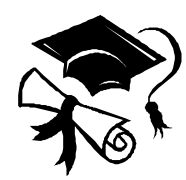

Marli Graniel Kinn

Orientador: Prof. Dr. Júlio César Suzuki

O trabalho sobre a Congada abordou a cidade e a condição sócio-cultural e espacial das pessoas que fazem a festa. Concentrando-se nos fazeres humanos, decorrentes de práticas sociais que proporcionaram à comunidade conquistas importantes em relação ao direito à cidade, chegamos ao cotidiano e ao modo de vida. Destacamos as formas de organização das pessoas e dos ternos de Congada na cidade, suas estratégias, arranjos, até atingirmos os conteúdos e a substância das manifestações e representações dos negros em Uberlândia - MG. Tratou-se de uma abordagem que foi sendo construída na direção de compreendermos as formas com que os congadeiros haviam estabelecido as condições mínimas para viverem na cidade. Por este caminho consideramos os costumes e as tradições e aos poucos fomos percebendo e analisando as desigualdades e as diferenças sociais. Para poder explicar as realidades dos congadeiros, suas práticas religiosas, políticas e comunitárias, fomos 

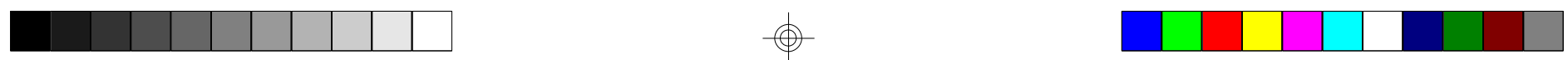

Teses de Doutorado e Dissertações de Mestrado Defendidas

(Maio de 2006 a Outubro de 2006), pp. 213 - 234

conhecendo as diversas origens sócio-espaciais destas pessoas. Essas realidades são desveladas quando abordamos a sua complexidade, a partir de múltiplas perspectivas. Por exemplo, os congadeiros de Uberlândia têm incluído, em suas manifestações, negociações que se concretizam na ocupação dos espaços públicos da cidade. $O$ trabalho discutiu também as relações mantidas entre o congadeiro e as várias instituições em que o grupo está envolvido. Nesse sentido, consideramos o histórico destas relações e nos deparamos com contradições que potencializam e medeiam embates, disputas e negociações entre grupos sociais e instituições, em relação aos usos do espaço. Desse modo, o estudo da Congada nos permitiu conhecer o modo de vida dos congadeiros, suas estruturas, heranças históricas, idéias, as quais continuam influenciando e transformando a consciência das pessoas e os processos que as redefinem em relação às vizinhanças, aos lugares, às redes sociais e à cidade.

\section{exeses ex}

\section{Os trilhos nas áreas urbanas : conflitos, desafios e oportunidades em dez cidades paulistas}

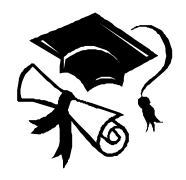

Luciano Ferreira da Luz

Orientador: Profa. Dra. Ana Maria Marques Camargo Marangoni

O destaque alcançado por um grupo significativo de cidades do interior do estado de São Paulo, que nas últimas décadas só foi mais reforçado pelo dinamismo econômico, evidenciou os aspectos que as projetam como pólos regionais. Nesse grupo de cidades ressalta-se a extrema urbanização, em muitas delas uma avançada conurbação com as vizinhas. Surgem aglomerações, que vão de 500 mil a mais de dois milhões de habitantes, formando uma rede de cidades que lideram o segundo maior mercado consumidor brasileiro. A atividade industrial crescente, a geração de empregos, o conseqüente crescimento demográfico e o espraiamento urbano, deram a essas cidades características de organização espacial muito própria e um sistema viário que não acompanhou esse crescimento, mais expressivo do que os das grandes capitais. Contudo, um elemento está presente em todas essas cidades e constitui um rico patrimônio histórico e, talvez, estratégico em seus futuros: a ferrovia. Nas dez maiores cidades do interior paulista, a presença marcante da velha estação e da linha férrea, que as cruzam e as dividem, são as heranças do processo de desmantelamento e total abandono da função ferroviária de transporte de passageiros de longo percurso. Quase sempre relegadas a funções acessórias no planejamento urbano, a ferrovia também esteve distante, encerrada entre seus muros, mantendo o diálogo com as cidades embaraçado ao longo do tempo. Essa pesquisa se propôs a fazer um levantamento geral desses patrimônios ferroviários, identificar suas interfaces atuais com o meio urbano, os novos agentes envolvidos na sua exploração e, principalmente, a visão e os usos pretendidos pelos municípios para as faixas ferroviárias e suas áreas lindeiras. Buscando amparo nas evoluções históricas, na análise de influências recíprocas e nas relações entre transporte e urbanismo, questiona-se a presença dos trilhos nessas áreas intensamente urbanizadas e são expostas as relações institucionais que devem ser consideradas para planejar e viabilizar o seu aproveitamento, seja pela implantação de novos equipamentos urbanos, pelo uso compartilhado de transportes ou mesmo pela sua erradicação. 

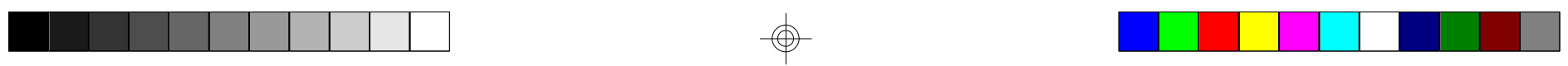

\section{Manifestações e contradições da metrópole de São Paulo no antigo bairro de Santana : a paisagem, o valor da terra, a intervenção urbana e o fenômeno da deterioração urbana}

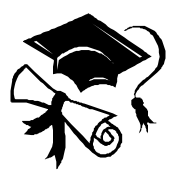

André Vinícius Martinez Gonçalvez

Orientador: Prof. Dra. Odette Carvalho de Lima Seabra

Esta dissertação parte da tese que o avanço da Metrópole de São Paulo em direção ao antigo bairro de Santana, em especial, a partir dos anos de 1950, gerou ao espaço geográfico local, uma considerável diversidade espacial, implicando hoje, um mosaico de realidades, tanto no aspecto de ocupação e uso do solo, como em relação às práticas sócio-espaciais. Essas realidades instauradas em Santana, na perspectiva do presente estudo são refletidas, sobretudo, a partir de duas questões: as intervenções urbanas, uma parcialmente efetivada nos anos de 1970, denominada Plano Cura Piloto de Santana, e outra em curso, intitulada Operação Urbana Vila Maria - Campo de Marte; e o fenômeno da deterioração urbana em Santana, fenômeno este, entendido como uma das contradições geradas a partir da reprodução do espaço urbano sob égide do sistema capitalista.

\begin{abstract}
A didática no processo de alfabetização de jovens e adultos : uma leitura do cotidiano a partir da geografia e de textos literários
\end{abstract}

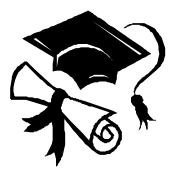

Vivian Christine Martins

Orientador: Profa. Dra. Sonia Maria Vanzella Castellar
Este trabalho traz o relato e a análise de uma experiência e uma reflexão sobre alfabetização de jovens e adultos. Buscamos, por meio da nossa vivência, discutir sobre estratégias didáticas e a contribuição do conhecimento geográfico e da literatura, visando evitar um ensino mecânico e sem sentido para o aluno no processo de alfabetização e que resulte numa aprendizagem significativa. Na nossa concepção sobre alfabetização, devemos promover o desenvolvimento de habilidades que garantam, não apenas, a aquisição do sistema de escrita

\section{Problemas ambientais urbanos : desafios e possibilidades para a escola pública}

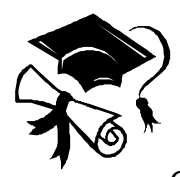

Orientador: Profa. Dra. Nidia Nacib Pontuschka
Este trabalho trata da abordagem dos problemas ambientais urbanos na Educação Básica, em especial, nas escolas da rede pública estadual. Procurou-se conhecer o trabalho feito, nesse sentido, por professores de Geografia de Carapicuíba, na Região Metropolitana de São Paulo, e foram desenvolvidos Estudos do Meio em duas escolas do referido município. Os temas para esses estudos foram sugeridos pelos professores e tratam de aspectos ambientais do entorno das escolas: a Lagoa de Carapicuíba e algumas das nascentes do rio Carapicuíba. 


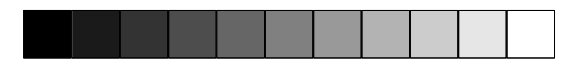

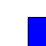

Teses de Doutorado e Dissertações de Mestrado Defendidas

(Maio de 2006 a Outubro de 2006), pp. 213 - 234

Com base nos resultados da pesquisa empírica, analisados à luz da bibliografia consultada, demonstrou-se as possibilidades do método do Estudo do Meio na construção, por educadores e educandos, de um conhecimento transformador sobre os problemas ambientais verificados no entorno das escolas. Do ponto de vista teórico trata-se, portanto, de questões relativas à complexa relação entre a sociedade e a natureza no ambiente urbano, e do papel da Educação diante da busca por uma melhor compreensão dos problemas ambientais. Desta forma, espera-se que este trabalho contribua para a superação desses problemas, por meio da ação política de cidadãos co-participantes da construção do conhecimento sobre o ambiente em que vivem.

\section{Território e macrossistema elétrico nacional: as relações entre privatização, planejamento e corporativismo}

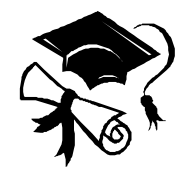

Mário Lamas Ramalho

Orientador: Prof. Dra. Maria Adélia Aparecida de Souza

Por meio do macrossistema elétrico brasileiro, essa pesquisa analisa o atrelamento de usos do território a interesses corporativistas. Esse sistema técnico passa por um processo de privatização a partir da década de 1990, acompanhado da inflexão das funções do Estado. Os planejamentos territorial e setorial são transformados, atrelando ainda mais a dinâmica territorial aos desígnios dos agentes privados. A energia elétrica passa a ser valorizada mais como bem mercantil do que como serviço público e questão estratégica nacional, o que traz mudanças ao significado das ações, dos objetos e, consequentemente, do próprio território. Mudanças essas realizadas por um país subdesenvolvido, onde as necessidades elementares da população não são plenamente garantidas. Tais questões são analisadas e discutidas, assumindo como princípio metodológico o espaço geográfico como instância social.

\section{Território usado e saúde: respostas do sistema único de saúde à situação geográfica de metropolização em Campinas - SP}

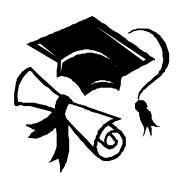

Mariana Vercesi de Albuquerque

Orientador: Prof. Dra. Maria Adélia Aparecida de Souza

A maior complexidade do mundo atual, trouxe novos desafios para as metodologias da geografia e da saúde pública, assim como, para a relação entre tais metodologias - instrumentais teóricos, técnicos e empíricos. A proposta deste trabalho é de que se pense a saúde a partir das noções de bem estar e uso do território, diante do mundo como uma totalidade concreta, no período técnicocientífico-informacional. Para a sistematização do conhecimento dos lugares foi utilizado o conceito de situações geográficas, definidas como um conjunto dos principais eventos que caracterizam as dinâmicas de cada lugar e seus sentidos futuros. As situações ajudam a identificar a dimensão dos desafios à concretização do bem estar em cada lugar, e lançam uma âncora no futuro para reflexão sobre a consolidação do Sistema Único de Saúde e a universalização da saúde. Nessa perspectiva, foi realizado o estudo da situação geográfica de metropolização, tendo como 
referencial empírico o município de Campinas SP. O objetivo foi observar como os serviços de saúde respondem aos desafios postos pelas contradições inerentes à situação geográfica de metropolização, isto é, a convivência as densidades técnicas, científicas e informacionais no uso do território com as extremas desigualdades socioespaciais de acesso a esses benefícios, oferecidos pela metrópole. A metodologia utilizada contribuiu para 0 entendimento das novas medidas de reestruturação adotadas recentemente pelo Hospital das Clínicas da UNICAMP, tomando por base os desafios estruturais do Brasil para a consolidação do SUS e para a universalização da saúde em relação à dimensão destes desafios postos - seus processos e profundidades - diante da situação de metropolização. O conceito de situação geográfica abre caminhos para as políticas públicas voltadas à compreensão dos desafios de concretização do bem estar conforme a dinâmica dos lugares; conhecimento que é, cada vez mais, requisitado pelos cidadãos e pelos gestores, para a melhoria das condições de vida e saúde da população.

\section{De arraial de Porto Alegre a cidade de Itaperuna : especificidade de uma urbanização com traços do rural}

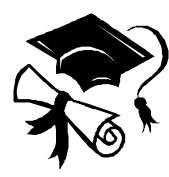

\section{Cátia Pereira dos Santos}

Orientador: Prof. Dra. Marta Inez Medeiros Marques

A urbanização é um processo que atinge grande parte do território brasileiro e que assume feições distintas conforme as especificidades de cada lugar. Estudar tais feições é uma forma de se compreender um pouco mais a dinâmica desse processo tão complexo e heterogêneo.Itaperuna, situada no interior do estado do Rio de Janeiro, é uma cidade que se formou com base na expansão da cafeicultura.
Por cerca de cinco décadas, a economia do município de Itaperuna esteve baseada nessa atividade. Situação que vai começar a se alterar com as repercussões da crise econômica mundial de 1929 na economia local. A partir daí, outras atividades, também ligadas ao campo, como a rizicultura e a pecuária leiteira, foram se desenvolvendo, enquanto a cafeicultura ia perdendo importância. Em meio às mudanças que vão ocorrendo no campo, a cidade vai se constituindo e se transformando, enquanto avança o processo de urbanização.Assim, este trabalho analisa as feições assumidas pelo urbano numa cidade com forte influência do meio rural. Nesse exercício, o bairro, sendo um espaço onde se desenvolvem relações imediatas diretas, apresenta-se como um nível de análise fundamental para a compreensão do urbano que lá se formou. O bairro reproduz numa escala menor, a forma particular como se dá o encontro do rural com o urbano que se materializa na cidade de Itaperuna.

\section{Mercosul e Can: os desafios da integração para a formação da comunidade sul- americana das nações}

Lauro Vanni

Orientador: Prof. Dr. José William Vesentini eseres es

Esta dissertação procura estabelecer uma análise comparativa entre o Mercosul e a Comunidade Andina das Nações, vislumbrando a formação da Comunidade Sul-Americana das Nações. Esta análise pode ser dividida em cinco etapas: a primeira descreve a base teórica de integração econômica e política, à luz da evolução comercial do século $X X$, suas motivações e os blocos regionais; a segunda 

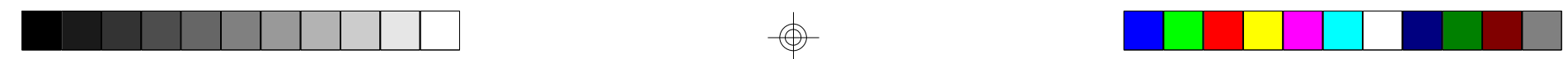

Teses de Doutorado e Dissertações de Mestrado Defendidas

(Maio de 2006 a Outubro de 2006), pp. 213 - 234

apresenta a origem e a evolução histórica da CAN; e a terceira, a origem e a evolução histórica do Mercosul, ambos com indicadores econômicos e sociais; a quarta etapa estabelece um comparativo entre os dois blocos no aspecto institucional, econômico-comercial, a deficitária integração de infra-estrutura, de energia e de telecomunicações, bem como o inexpressivo enfoque dado à área social; na última etapa são apresentadas as perspectivas regionais para o Brasil, a evolução e as limitações dos projetos de integração, o novo paradoxo na integração regional bem como uma agenda prospectiva. Estes elementos poderão servir de base para o estudo de outros temas ligados a integração regional.

$$
\text { exter ex }
$$

Caminhos e descaminhos: a ferrovia e a rodovia no Bairro Barcelona em Sorocaba/SP

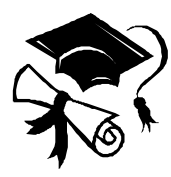

Emerson Ribeiro

Orientador: Profa. Dra. Glória da Anunciação Alves

Este estudo problematiza a produção espacial de um bairro mediante os caminhos que nele chegam, como a ferrovia e a rodovia. Procura discutir como os caminhos que favoreceram o processo de industrialização e urbanização, sendo resultado das relações de produção de uma sociedade. Assim, o estabelecimento de uma sociedade num dado local advém também da importância dos caminhos criados e elaborados socialmente para esse fim, dando uma continuidade e interferindo nas relações de produção em seu sentido mais amplo: da vida, de mercadorias, de espaços.Esse movimento possibilita a reprodução das esferas produtivas, fazendo parte da sociedade urbana e industrial. Num tempo próprio do bairro, no caso o Bairro Barcelona na cidade de Sorocaba$\mathrm{SP}$, este tem seu cotidiano transformado ao mesmo tempo em que essa escala do lugar faz parte de um movimento de reprodução do capital que articula outras escalas. Entender esse processo exige que se discuta a expansão da cidade, bem como de sua centralidade e como, ao mesmo tempo, se fragmentam e articulam os espaços, transformando a realidade local.

\footnotetext{
O mapa no estudo do ambiente: uma proposta didática

Marcos Nicol Giusti

Orientador: Prof. Dr. Marcello Martinelli

O tema central da nossa monografia é a utilização do mapa e dos recursos cartográficos no estudo da Geografia. O trabalho está organizado em três partes principais. Na primeira parte apresentamos as principais correntes teórico-filosóficas, que subsidiam a prática construtivista no trabalho pedagógico da construção do conhecimento, do qual participam professor e aluno. Ainda nesta parte,

eses eses

voltamos a nossa atenção para a prática educativa no ensino da Geografia finalizando com uma menção da proposta dos livros didáticos. No Capítulo II, após uma introdução sobre a história do desenvolvimento da Cartografia, passamos à consideração da utilização pedagógica do mapa no ensino da Geografia. No Capítulo III, apresentamos um ensaio de proposta de atividade com mapas e outras representações para o estudo do ambiente. Dirigimos o nosso foco para seqüências didáticas que abordam o estudo do relevo e da água. Apoiamos a nossa proposta em duas situações didáticas, uma delas com professores da rede estadual de ensino fundamental e médio e a outra decorrente da nossa experiência dentro de sala de aula como professor de Geografia em séries do IIํ ciclo do Curso Fundamental.
} 


\section{Foz do Iguaçu: cidade rede sul-americana}

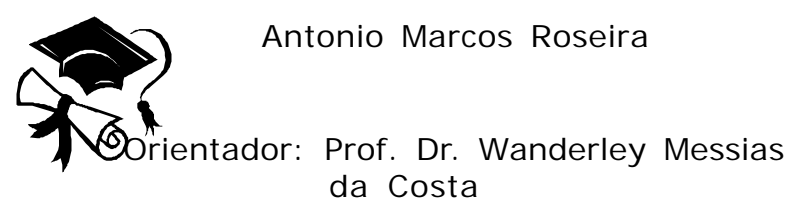

Foz do Iguaçu, como a mais importante cidade da Tríplice Fronteira, possui um conjunto de características que remetem à condição geopolítica contemporânea. A cidade surgiu como Colônia Militar no século XIX, resultado de tensões entre os países da Bacia do Prata, em relação ao controle das fronteiras e do território. Foz do Iguaçu, que junto a Ciudad Del Este (Paraguai) e Puerto Iguazu (Argentina) forma uma espécie de metrópole tri- nacional, sempre foi foco privilegiado de interesses geopolíticos. Se o seu surgimento esteve atrelado às estratégias militares de controle territorial, o seu crescimento e desenvolvimento foram derivados de políticas do governo federal concernindo todo o Oeste Paranaense. A construção BR-277, da Ponte Internacional da Amizade e da Usina Hidrelétrica de Itaipu revela o valor da Tríplice Fronteira e de Foz do I guaçu na relação entre os países do Cone Sul. Por meio da concentração de atividades turísticas e das práticas de comércio ilegal junto a Ciudad Del Este, a cidade se coloca numa condição única dentro de um cenário de integração regional do Mercosul. Ao mesmo tempo em que é um núcleo privilegiado dessa integração, após décadas de atritos geopolíticos entre Brasil, Paraguai e Argentina, Foz do Iguaçu expõe um emaranhado de problemas envolvendo o controle da fronteira, com reflexos políticos, econômicos e sociais para toda a América do Sul.

\section{Identidade e memória da comunidade russa na cidade de São Paulo}

Alexandre Vorobieff

\author{
Orientador: Prof. Dr. André Roberto \\ Martin
}

O presente estudo enfoca os imigrantes russos que vieram para o Brasil e acabaram se concentrando na cidade de São Paulo e suas dificuldades para iniciar uma nova vida no país. Através dessa pesquisa, procuro entender os processos históricos que os trouxeram para o país, como a comunidade russa se estruturou diante da nova realidade, assim como destacar os fatores que dão coesão ao grupo dentro da sociedade paulistana e brasileira. Outro objetivo é a construção da identidade da comunidade russa local, utilizando os relatos e memórias dos imigrantes russos. A importância dessa pesquisa está relacionada a diversos ramos da geografia, dentre as quais destacamos a geografia da população, a geografia urbana, a geografia política e a geografia cultural, entre outras áreas do conhecimento. Para realizarmos esta pesquisa, utilizamos o método fenomenológico, buscando através da análise dos depoimentos e outros documentos as principais características da alma russa, além de utilizar o conjunto de procedimentos conhecidos como História oral. A questão da coesão cultural dentro da comunidade russa local é muito forte, mesmo após décadas dos grandes fluxos imigratórios. Apesar da assimilação da cultura brasileira, muitos descendentes de russos, mantém suas tradições culturais e religiosas, como por exemplo, através da organização de grupos folclóricos de dança, como os conhecidos Volga, Troyka e Balalaica. A fé ortodoxa, apesar do reduzido número de fiéis, devido aos falecimentos de muitos imigrantes idosos ou pela mudanças de membros da comunidade para outros locais, todas as paróquias da cidade de São Paulo continuam ativas. A pesquisa revela um pouco da memória da comunidade russa que se instalou no Brasil, principalmente na cidade de São Paulo. 


\section{Geografia e cartografia do turismo}

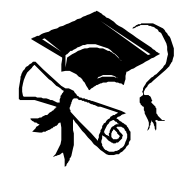

Iara Sakitani

Orientador: Prof. Dr. Marcello Martinellii

A cartografia do turismo faz parte do conjunto de representações gráficas que compõem a cartografia temática. O presente estudo, inserido no contexto da cartografia temática, tem como objetivo elaborar uma proposta cartográfica para o turismo. Para a elaboração de tal proposta, foi resgatada a evolução do saber tanto da geografia quanto da cartografia. Tal tarefa possibilitou uma compreensão do papel da cartografia nas representações turísticas. Em um segundo momento, dez mapas turísticos foram analisados, demonstrando-se as várias formas de representação do turismo em mapas, e a acessibilidade desses mapas mundialmente conhecidos. A última etapa da investigação apresenta um estudo de caso do município de São Bento do Sapucaí - SP; há uma caracterização do município explorando os aspectos sociais e naturais relacionados ao turismo. O estudo de caso associado aos fundamentos teóricos-metodológicos apresentados no $1^{\circ}$ capítulo da dissertação possibilitou a elaboração de um mapa das unidades de potencial turístico para o município de São Bento do Sapucaí. Tal mapa expressa o raciocínio de síntese elucubrado ao longo do processo investigativo.

\section{O circuito inferior da economia urbana na cidade de São Paulo no período da globalização}

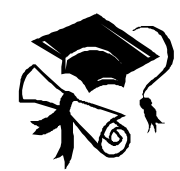

Marina Regitz Montenegro

Orientador: Prof. Dra. Maria Laura Silveira

No presente trabalho, buscamos realizar uma análise sobre as dinâmicas que perpassam e definem o circuito inferior da economia urbana (Santos, 1978) na cidade de São Paulo no período atual, ou seja, no período da globalização. Segundo Santos, a segmentação presente na sociedade urbana dos países subdesenvolvidos em relação às possibilidades de satisfação das necessidades cria diferenças quantitativas e qualitativas no consumo, as quais, por sua vez, são a causa e o efeito da existência de diferentes circuitos de produção, de distribuição e consumo. Enquanto o circuito superior constitui o resultado direto das modernizações que atingem o território, o circuito inferior compreende as formas de fabricação não-capital intensivo, os serviços não modernos fornecidos a varejo e o comércio de pequena dimensão, voltados sobretudo ao consumo dos mais pobres. Enquanto o circuito superior alimenta-se da aceleração contemporânea global, o circuito inferior é moldado pelos tempos e formas do lugar. A partir da seleção de determinadas áreas da cidade de São Paulo que aparecem como verdadeiros "focos de concentração" do circuito inferior, - no Largo Treze de Maio e nos distritos Sé, República, Santa Cecília e Bom Retiro procuramos compreender como se caracteriza este circuito hoje e, também, como este se relaciona com as variáveis centrais do período atual, ou seja, a técnica, a informação, o consumo, a publicidade e as finanças. Orientados pela preocupação de ver a cidade como uma totalidade interconectada por diversas divisões do trabalho, em diferentes pedaços do meio construído, buscamos entender como o território constitui um abrigo para os atores não-hegemônicos, na medida em que comporta atividades tão distintas e distantes em termos de graus de organização e de capital. 

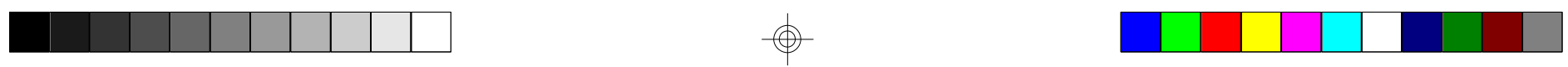

\section{A política nacional de recursos hídricos (PNRH) e o federalismo no Brasil}

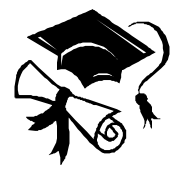

\section{Ana Cristina Fonseca Tomaz}

Orientador: Prof. Dr. Wanderley Messias da Costa

Tema foi trabalhado à luz da geografia humana e foram analisadas as dificuldades em se implementar a Política Nacional de Recursos Hídricos (PNRH) na atual crise federativa brasileira. Foi realizado levantamento com base em documentos técnicos de instituições nacionais e internacionais acerca da escassez e disponibilidade de água no Brasil e no mundo; fez-se também pesquisa em artigos multidisciplinares a respeito do funcionamento da PNRH em diversas regiões do país. A dissertação propõe uma alternativa de gestão, centralizada no plano nacional, que permite ao mesmo tempo a cooperação entre os entes federados e a competição necessária para o desenvolvimento individual.

\section{A expansão urbana de Peruíbe : aspectos legais e a realidade do uso e ocupação da terra}

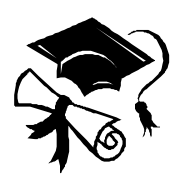

Mônica Bárbara Ribeiro

Orientador: Prof. Dr. Flávio Sammarco Rosa

A cidade de Peruíbe apresenta, nas duas últimas décadas uma dinâmica que se traduz em um intenso crescimento urbano. A área urbanizada se expande em decorrência da implantação de

ses

novos loteamentos, modificando as características físicas do território, que passa a ser incorporado à cidade. Este estudo analisa a dinâmica urbana do município, confrontando a legislação vigente com a real configuração do território, identificando os padrões de uso da terra urbana. Essa investigação considera, também, o processo de ocupação do município ao longo do tempo, envolvendo a fotointerpretação de fotos aéreas de vários períodos (1962, 1997 e 2001/02). Este tema mostra-se como um excelente campo de aplicação de técnicas cartográficas baseadas na cartografia digital, no Sensoriamento Remoto e nos Sistemas de Informações Geográficas (SIGs).

Les eses

Ocupar e resistir: problemas da habitação no centro pós-moderno (SP)

\section{Jean Pires de Azevedo Gonçalves}

Orientador: Prof. Dra. Amélia Luisa Damiani

Esta pesquisa procura situar a produção do espaço no contexto das operações de reurbanização na cidade de São Paulo, especificamente, a "revitalização do centro". Tais abstrações se colocam na realidade reduzindo as potencialidades do urbano, este entendido como lugar do encontro, a simples troca de mercadorias e relações contratuais entre "agentes" sociais, ora personificados em capitalistas, ora, em proletários. Neste sentido, o espaço, de modo estratégico, é produzido como espetáculo, ideologia e meio de segregação, dentro dos limites de uma economia capitalista que se apresenta agora como crise do trabalho. Diante destas circunstâncias, as relações de produção não se efetivam totalmente e é cada vez maior uma crescente população de trabalhadores que não consegue vender sua força de trabalho, devido à redução de sua oferta no mercado, e que, por isso, não encontra lugar nesta economia. Através destas questões, buscou-se definir táticas de resistência de parte desta população, notadamente os semtetos, perante a revitalização do centro. Daí, o problema da habitação não se resumir às restrições físicas da residência, mas a luta pela cidade, a própria existência e o habitar. 


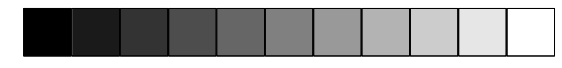

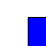

Teses de Doutorado e Dissertações de Mestrado Defendidas

(Maio de 2006 a Outubro de 2006), pp. 213 - 234

Transformações urbanas recentes em Tiradentes-MG: anos 80 e 90 do século XX

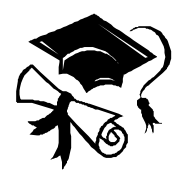

Helcio Ribeiro Campos

Orientador: Profa. Dra. Amália Inês Geraiges de Lemos

Esse trabalho, estreitado com a linha de pesquisa do Programa de Pós-graduação em Geografia Humana, tem por objetivo maior indicar as transformações recentes ocorridas no espaço urbano da cidade de Tiradentes - MG, ou seja, a partir da década de 1980. A fim de demonstrar isso, houve um estudo sobre a formação socioespacial da cidade ao longo do tempo - desde o século XVIII até 2005 , incluindo aí a influência do turismo - que resgatou o dinamismo econômico local após os anos 1960. Desse modo, Tiradentes passa a receber investimentos públicos e privados que incrementam o turismo e, assim, atraem os imigrantes; valorizam seus terrenos e imóveis; transformam o Centro Histórico cada vez mais numa região de comércio e em processo de gentrificação; expandem intensamente a cidade, desde a década de 1980, através de loteamentos nos bairros. Nesse contexto, o trabalho é finalizado com as perspectivas da expansão urbana que estão se formando em Tiradentes.

$$
\text { eses eses }
$$

Os chapas e o seu papel no meio técnicocientífico-informacional e na logística dos transportes no Brasil: estudo de caso na cidade de Ribeirão Preto/SP (2003-2006)

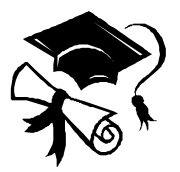

Pedro Mezgravis

Orientador: Profa. Dra. Rosa Ester Rossini

Carregar e descarregar caminhões, informar e orientar motoristas. Estas são as principais atividades realizadas por trabalhadores conhecidos como Chapas, que se fazem presentes praticamente na totalidade do Território Brasileiro. Nesta perspectiva, as diferentes formas de uso deste território são os preceitos principais para a observação e estudo destes trabalhadores. Portanto, é possível pensá-los a partir dos mais diferentes referenciais, desde um debate clássico como o urbano/rural, como as questões agropecuárias no Brasil, desenvolvimento urbano, transportes e fluidez territorial, entre tantos outros. Buscamos compreender sua posição diante das Normas da Moderna Logística e do Transporte Rodoviário de Cargas no Brasil. Estudo de caso em Ribeirão Preto.

$$
\text { exes ex }
$$

Geografia e relações raciais: desigualdades sócio-espaciais em preto e branco

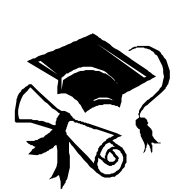

Antonio Carlos Malachias

Orientador: Prof. Dr. Francisco

Capuano Scarlato
A presente pesquisa tenta analisar as idéias e ideologias raciais em perspectiva geográfica. Busca demonstrar que estas idéias são parte de um sistema de ações indissociáveis dos arranjos espaciais. Estes arranjos espaciais são desigualmente usaos e acessados por negros e brancos. O uso diferenciado e desigual do espaço geográfico gera por parte do grupo negro a formulação de outras idéias (ações) em reação ao primeiro. 

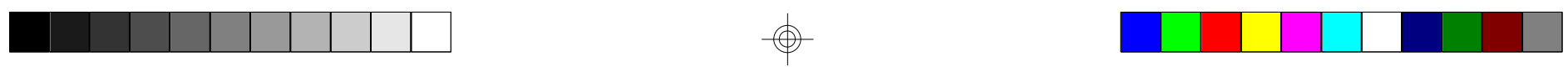

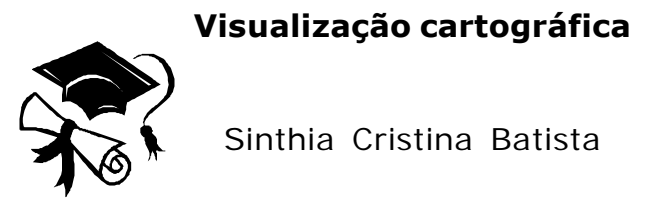

Orientador: Profa. Dra. Maria Elena Ramos Simielli

Apresentando-se no plano teórico, este trabalho expõe novos referenciais em Cartografia temática discutidos internacionalmente por meio da Visualização Cartográfica (para alguns autores, Visualização Geográfica ou GVIS "Geographic Visualization"). Seu arcabouço parte de pressupostos que avaliam a entrada do meio digital e da visualização científica no processo de construção cartográfica, considerando as mudanças teóricas da própria Geografia e

$$
\text { Leses }
$$

Para onde cresce a cidade : dinâmica de expansão urbana e caracterização urbanoambiental em área da bacia do

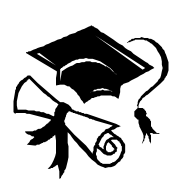
Guarapiranga

Mariana Bielavsky

Orientador: Prof. Dr. Ailton Luchiari

Essa pesquisa trata do crescimento urbano e implicações ambientais de uma área na bacia avaliando os paradigmas vigentes que, conseqüentemente, transformaram o modo de investigar, construir conhecimentos e refletir sobre o espaço geográfico.Busca-se contribuir, a partir da sistematização de novos conceitos, para a compreensão e o avanço da discussão sobre as representações cartográficas no corpo da Geografia brasileira. Ressalta-se ainda o uso de uma Cartografia Geográfica que priorize o desenvolvimento do raciocínio espacial no bojo de suas representações para a compreensão de fenômenos geográficos. Mergulhados neste debate será analisado um protótipo aplicativo em Visualização Cartográfica: um ambiente de jogos com enfoque no ensino de Geografia com vistas à criação de um ambiente de pesquisa e aprendizagem. Por fim perfilaremos um debate sobre novos usos e eixos de discussão referentes à Cartografia nacional.

\section{Análise da qualidade ambiental urbana na bacia hidrográfica do Rio Itaquera no município de São Paulo : um ensaio metodológico}

Maria Aparecida Oliveira

Orientador: Prof. Dr. Ailton Luchiari do Guarapiranga. Essa área abrange parte dos municípios de São Paulo, Itapecerica da Serra e Embu Guaçu.O intuito é apresentar a evolução urbana da área entre os anos 1962 e 2001, com analises de fotografias áreas. Em uma escala intra-urbana, a pesquisa apresenta a interpretação de fotografias áreas para o ano de 2001 criando a carta de áreas homogêneas urbanas. Os principais dados dessa pesquisa são para o ano de 2001, de modo que pudemos os indicadores sócio-demográficos dos dados do censo do IBGE realizado para o ano de 2000. Com todos esses dados, podemos apontar os vetores de crescimento urbano da área, assim como seus problemas sócio-ambientais.

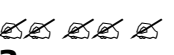

O presente trabalho é um ensaio metodológico baseado na análise geossistêmica da paisagem com a aplicação de geotecnologias e técnicas de análise estatística multivariada, para elaboração de uma carta de qualidade ambiental urbana com base nos condicionantes naturais e socioeconômicos da paisagem. A metodologia desenvolvida, foi aplicada a uma bacia hidrografia do Rio Itaquera na zona leste do município de São Paulo. A proposta 

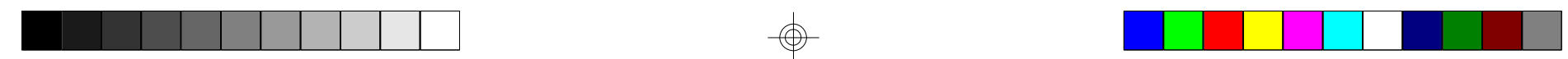

Teses de Doutorado e Dissertações de Mestrado Defendidas

(Maio de 2006 a Outubro de 2006), pp. 213 - 234

metodológica incorporou dados do meio ambiente físico, meio ambiente construído e do meio socioeconômico. O resultado obtido foi uma carta de unidades de paisagens urbanas e posteriormente uma carta de qualidade ambiental urbana, no contexto da bacia hidrográfica. A escala final das cartas é 1:10 000 e esta inserida dentro de um sistema de informações geográficas. O que possibilita a realização de atualizações periódicas para efeito de monitoramento dos padrões de qualidade ambiental

\section{A distribuição espacial de superfícies impermeáveis na porção noroeste do município de São Paulo obtidas a partir de imagens orbitais}

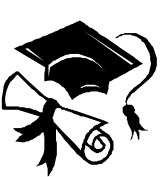

Erika Megumy Tsukada

Orientador: Prof. Dr. Tarik Rezende de Azevedo

Neste trabalho, procuramos avaliar o uso de técnicas de sensoriamento remoto para a geração de mapa de impermeabilidade em áreas urbanas e periurbanas, por meio da classificação pelo processamento digital da imagem orbital TM Landsat, aferida através da interpretação visual de ortofoto digital. A área de estudo conta com aproximadamente $113 \mathrm{~km} 2$, abrangendo as
Subprefeituras Perus e Pirituba/Jaraguá, situadas na região noroeste do Município de São Paulo. Para o desenvolvimento deste trabalho foram utilizadas imagens TM Landsat, adquiridas nos anos de 1991 e 2001. As imagens foram decompostas em componentes - solo, vegetação e sombra - por meio do modelo linear de mistura espectral. Técnicas de segmentação, classificação por região e edição de imagens foram utilizadas para mapear as condições de permeabilidade das áreas urbanizadas. Os resultados mostraram que houve um aumento de 23,39\% das áreas impermeáveis, devido à expansão urbana. O procedimento adotado mostrou-se satisfatório para a detecção de tipos de cobertura da terra, entretanto, houve a necessidade de edição nas regiões onde houve a mistura entre classes de uso. Acreditamos que esses procedimentos podem ser aplicados a pequenas áreas, pois em grandes extensões pode haver a necessidade de muitas edições.

$$
\text { exters }
$$

\section{Análise dos biótipos na bacia hidrográfica do córrego águas espraiadas- São Paulo - SP}

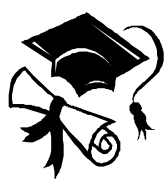

Lucilia Blanes

Orientador: Prof. Dr. Jurandyr Luciano sanchez Ross

A presente dissertação tem como objetivo discutir a importância da preservação das condições naturais em áreas urbanas. Neste sentido procedeu-se o estudo da impermeabilização de lotes inseridos em biótopos (unidades de paisagem) encontradas na bacia hidrográfica do Córrego Águas Espraiadas, a qual apresenta-se totalmente urbanizada. Realizamos uma ampla caracterização ambiental e histórica da área estudada, através da análise de variáveis de lotes amostrais. Utilizamos nesse trabalho um fator chamado BAF (Fator de Biótopo de Área), cálculo muito utilizado no planejamento de áreas urbanizadas na cidade de Berlin. Este trabalho pretende oferecer subsídios para o fomento de ações administrativas que levem à preservação de ambientes naturais e para a melhor qualidade de vida urbana. 


\section{O geoprocessamento na gestão ambiental em terras indígenas : uma experiência com etnomapeamento junto à comissão pró-índio do Acre}

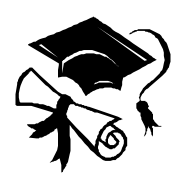

Antônio Luís Andrade de Carvalho

Orientador: Profa. Dra. Regina Araújo de Almeida

O objetivo central deste trabalho é o desenvolvimento de materiais didáticos direcionados às populações indígenas no estado do Acre, Brasil, envolvendo professores e agentes agroflorestais sob a coordenação da Comissão Pró-Índio - CPI/AC. A introdução de noções básicas de orientação e localização e o manuseio de instrumentos como a bússola e mais especificamente o GPS - Sistema de Posicionamento Global - são bases para o conseqüente domínio na cartografia. Através da combinação de fotografias aéreas e imagens de satélite com informações devidamente orientadas pela determinação dos pontos de controle favorecem a elaboração de mapas, e assim atingem a possibilidade de gerenciar e planejar o uso do solo com base georeferenciada. A geração de cartas geográficas referenciadas propiciam estudar e implementar, de maneira mensurável, o processo de definição das políticas de ocupação de suas terras, permitindo a discussão de problemas locais e a devida estruturação de ações que visam o planejamento territorial e ambiental. Aspectos relevantes como o manejo de recursos naturais, o cálculo de áreas, a avaliação da produção e inventário, a demarcação e monitoramento em áreas de fronteira sujeitas a invasões, áreas de refúgio de fauna, de culturas e locais sagrados assim como as trilhas utilizadas serão focalizados na composição de mapas de diagnóstico ambiental. Como resultante, elaborar e implementar a produção de textos bilíngües em co-autoria com professores e agentes agroflorestais indígenas, considerando a acessibilidade às tecnologias referentes à cartografia e sua importância no etnomapeamento.

\section{Indicadores geomorfológicos de mudanças ambientais no sistema fluvial do Alto Tietê (município de São Paulo) : pesquisa documental}

Deborah Luciana Ribeiro de Carvalho

Orientador: Profa. Dra. Cleide Rodrigues

A pesquisa concentra-se no estudo dos efeitos da urbanização nos sistemas fluviais meândricos do Rio Tietê (município de São Paulo). O objetivo central reside na avaliação do potencial de utilização de documentação técnica-histórica como fonte em pesquisas geomorfológicas e para a leitura dos geoindicadores de mudanças ambientais provocadas pela urbanização em países do meio tropical úmido. Para realizar essa tarefa, se fez necessário investigar relatórios técnicos produzidos e arquivados, no Departamento de Águas e Energia do Estado de São Paulo e na Fundação Energia e Saneamento, quando da execução de obras de engenharia no referido sistema, por meio do levantamento de fontes de informação, observação sistemática de documentos utilizando indicadores geomorfológicos (forma, materiais e processos) específicos para sistemas fluviais e para a modalidades de intervenção antrópica da urbanização. Como resultados da pesquisa foram produzidos inventários e fichas descritivas desses documentos e a partir desses, tabelas e séries históricas de dados geomorfológicos. 


\section{Identidade e territorialidade: os quilombos e a educação escolar no Vale do Ribeira}

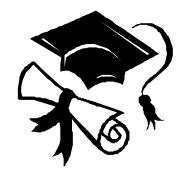

Lisângela Kati do Nascimento

Orientador: Profa. Dra. Sueli Angelo Furlan

A presente dissertação aborda o estudo da relação entre o ensino da geografia e a identidade cultural das comunidades remanescentes de quilombos, localizadas no Vale do Ribeira, Estado de São Paulo. A partir da análise das propostas didáticas para o ensino de geografia desenvolvido nas escolas públicas dos municípios de Eldorado e Itapeúna (Ensino Fundamental II) e também na Escola Estadual localizada no quilombo Ivaporunduva (Ensino Fundamental I), este trabalho busca identificar elementos que contribuem (ou não) para a (re) construção da identidade cultural quilombola.A região do Vale do Ribeira concentra as maiores manchas contínuas remanescentes de Mata Atlântica do Brasil e também apresenta os piores indicadores sócio-econômicos do Estado de São Paulo. Nesse contexto, a preservação ambiental e desenvolvimento econômico se chocam. Dessa maneira, os projetos de construção de barragens para o rio Ribeira de Iguape ganham força interna. Com isso, grande parte das comunidades de quilombos, situada às margens do rio Ribeira, sofrem o risco de perder seus territórios. A identidade cultural das comunidades de quilombos no Brasil está relacionada com o território onde vivem. As comunidades do Vale do Ribeira ameaçadas de expropriação territorial lutam pelo direito à propriedade da terra (Artigo 68 da Constituição), o que força a se (re) pensarem como quilombolas em vários aspectos da vida social. É nesse bojo, que a preocupação com uma escola que valorize sua identidade cultural adquire importância. A partir de entrevistas com lideranças quilombolas, professores e alunos, como também observação de aulas, pudemos constatar que entre a escola que desejam e a que se apresenta no cotidiano requer um caminho a ser trilhado. Ao pesquisar o papel do ensino de geografia identificamos importantes ações no sentido de valorizar o lugar de vivência do aluno. Encontramos ainda ações didáticas que reforçam a homogeneização cultural, negando a pluralidade cultural existente na vida escolar.

exes es

\section{Impactos sobre remanescentes florestais de Mata Atlântica na região metropolitana de São Paulo : um estudo de caso da mata da fazenda Tizo}

\section{Renê Costa}

Orientador: Profa. Dra. Sueli Angelo Furlan

A expansão da área urbana da Região Metropolitana de São Paulo vem pressionando, fragmentando e suprimindo os últimos remanescentes de florestas de Mata Atlântica. No entanto, a reconstituição do processo histórico de exploração florestal na região oeste da Grande São Paulo demonstrou que a fragmentação e a deterioração dos remanescentes advêm de atividades econômicas anteriores a urbanização, quando ainda a região estava inserida em uma paisagem de matriz rural. A dinâmica urbana na região oeste da grande São Paulo, a partir de 1990, foi responsável pela formação de aterros, assentamentos habitacionais de baixo, médio e alto padrão e pelo Rodoanel Mário Covas produzindo uma trama espacial marcada pelo contraste e pela fragmentação.Em meio a essa trama, a mata da Fazenda TIZO, localizada na divisa dos municípios de São Paulo, Taboão da Serra, Embu, Cotia e Osasco apresenta uma formação florestal diversificada, caracterizada como mata em estágio sucessional médio à 


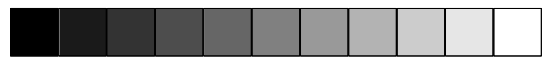

tardio com dinâmica regressiva. No intuito de resgatar o potencial ecológico dos remanescentes visando o desenvolvimento sucessional progressivo, nosso trabalho demonstrou à necessidade de um manejo que viabilize o aumento da área florestal efetiva e a diminuição do efeito de borda por meio de ações como a integração dos remanescentes, o controle dos cipós e dos bambus nas áreas de clareiras e nas bordas e a formação de um corredor com as matas circundantes, entre elas a mata da Caixa Beneficente da Polícia Militar e outras áreas privadas. 
